\title{
Effect of obesity on ecocardiographic parameters and vertebral heart size (VHS) in cats
}

\section{Efeito da obesidade sobre parâmetros ecocardiográficos e VHS em gatos}

\author{
Fúlvia Bueno de Souza'; Danilo Velazquez Golino²; Shayra Peruch Bonatelli; \\ Angélica Alfonso ${ }^{4}$; Maria Jaqueline Mamprim"; Júlio César Carvalho Balieiro ${ }^{6}$; \\ Alessandra Melchert ${ }^{7}$; Priscylla Tatiana Chalfun Guimarães-Okamoto ${ }^{7}$; Maria \\ Lucia Gomes Lourenço ${ }^{7 *}$
}

\section{Highlights:}

The echocardiographic measurements and thorax radiography in both obese and non-obese cats, establishing a relationship between the obtained data and Body Condition Score (BCS), Body Mass Index (BMI) and Vertebral Heart Size (VHS).

The implications of obesity on the feline cardiovascular system through echocardiographic assessment are yet to be fully established and studies regarding the subject are scarce.

The parameters examined in this study could be used to improve the study of complications in obesity in cats.

\begin{abstract}
The objective of this study was to correlate cardiovascular parameters with obesity in adult cats. Forty mixed-breed cats ( 20 obese and 20 controls) underwent echocardiographic measurements and thoracic radiography to establish a relationship between the obtained data and the body condition score (BCS), body mass index (BMI), and vertebral heart size (VHS). Systolic arterial pressure (SAP) was also studied in 15 obese cats. Compared to the control cats, obese cats presented higher VHS values across several measurements, but among the echocardiographic parameters, only the difference in the left ventricular free wall at diastole was statistically significant. A positive relationship was established
\end{abstract}

\footnotetext{
${ }^{1}$ Discente do Curso de Mestrado do Programa de Pós-Graduação em Medicina Veterinária, Departamento de Clínica Veterinária, Faculdade de Medicina Veterinária e Zootecnia, Universidade Estadual Paulista, UNESP, Botucatu, SP, Brasil. E-mail: ful. bueno@gmail.com

2 Discente do Curso de Medicina Veterinária, Faculdade de Medicina Veterinária e Zootecnia, UNESP, Botucatu, SP, Brasil. E-mail: danilo.golino@gmail.com

3 Discente do Curso de Doutorado do Programa de Pós-Graduação em Biotecnologia Animal, Departamento de Reprodução Animal e Radiologia Veterinária, Faculdade de Medicina Veterinária e Zootecnia, UNESP, Botucatu, SP, Brasil. E-mail: shayrabonatelli@gmail.com

4 Discente do Curso de Doutorado do Programa de Pós-Graduação em Medicina Veterinária, Departamento de Clínica Veterinária, Faculdade de Medicina Veterinária e Zootecnia, UNESP, Botucatu, SP, Brasil. E-mail: alfonso_angelica@ymail.com

5 Prof ${ }^{a}$, Departamento de Reprodução Animal e Radiologia Veterinária, Faculdade de Medicina Veterinária e Zootecnia, UNESP, Botucatu, SP, Brasil. E-mail: jaqueline.mamprim@unesp.br

6 Prof., Departamento de Nutrição e Produção Animal, Universidade de São Paulo, USP, Pirassununga, SP, Brasil. E-mail: balieiro@usp.br

7 Profas, Departamento de Clínica Veterinária, Faculdade de Medicina Veterinária e Zootecnia, UNESP, Botucatu, SP, Brasil. E-mail: alessandra.melchert@unesp.br; tatiana.okamoto@unesp.br; maria-lucia.lourenco@unesp.br

* Author for correspondence
} 
between body weight, left ventricular internal diameter at diastole, and left ventricular free wall at diastole. Positive relationships were also observed between BMI and diameter of the aorta, BCS and the left ventricular free wall at diastole, VHS and the left atrium, and the left atrial to aortic root diameter ratio and the left ventricular internal diameter at diastole. SAP was higher in obese cats and presented a positive correlation with body weight. Obesity correlated with an increase in SAP and with some echocardiographic and radiographic cardiac measurements in adult cats. Further studies are needed to better assess the effects of obesity on the cardiovascular system of cats and to reassess the parameters related to body weight and condition.

Key words: Feline. Body weight. Thoracic radiography. Echocardiography.

\section{Resumo}

O objetivo deste estudo foi correlacionar parâmetros cardiovasculares com obesidade em gatos adultos. Foram utilizados 40 gatos mestiços ( 20 obesos e 20 controles) avaliados por meio de medidas ecocardiográficas e radiografia de tórax, estabelecendo relação entre os dados obtidos e escore de condição corporal (ECC), índice de massa corporal (IMC) e tamanho do coração vertebral (VHS). A pressão arterial sistólica (PAS) também foi estudada em 15 gatos obesos. Os gatos obesos apresentaram valores mais altos de VHS nas várias medições realizadas em comparação com gatos normais, mas apenas a diferença na medida da parede livre do ventrículo esquerdo na diástole foi estatisticamente significativa nos parâmetros ecocardiográficos. Uma relação positiva foi estabelecida entre o peso corporal, o diâmetro interno do ventrículo esquerdo na diástole e a parede livre do ventrículo esquerdo na diástole. Outras relações positivas estabelecidas, incluem o IMC com o diâmetro da aorta (AO), ECC com parede livre do ventrículo esquerdo na diástole, VHS com o átrio esquerdo (AE), e da relação do átrio esquerdo com o diâmetro da raiz da aorta (AE: Ao) com diâmetro interno do ventrículo esquerdo na diástole. A PAS foi maior em gatos obesos e apresentou correlação positiva com o peso corporal. A obesidade se correlacionou com aumento da PAS, e com aumento em medidas ecocardiográficas e radiográficas em gatos. Mais estudos são necessários para melhor avaliar os efeitos da obesidade no sistema cardiovascular da espécie, e reavaliar os parâmetros relacionados ao peso e condição corporal.

Palavras-chave: Felino. Peso corporal. Radiografia de tórax. Ecocardiografia.

\section{Introduction}

Obesity is considered the most prevalent form of pet malnutrition in the western hemisphere. However, it has become increasingly more common even in developing countries (Toll, Yamka, Schoenherr, \& Hand, 2010; Clark \& Hoenig, 2016).

The incidence of obesity in cats during the $1970 \mathrm{~s}$ exceeded $20 \%$ depending on the epidemiological site, and usually varied between 15 and 35\% (Diez \& Nguyen, 2006; Zoran, 2009). The causes of obesity in pets, as in humans, are multifactorial. It is the result of an imbalance between energy intake and expenditure, with either excessive intake or inadequate expenditure leading to a positive energy balance (Toll et al., 2010).
The most commonly applicable diagnostic method for obesity is the determination of an animal's body condition score (BCS). The BCS may be determined using the five-point and ninepoint scales as long as the same system is used in all cases (Linder \& Mueller, 2014).

Assessing the body mass index (BMI) is simple and the parameter is easily employed. It indicates the relationship between body weight in kilograms and body surface in square meters. The importance of the BMI in cases of obesity lies in its curvilinear relationship with mortality. That is, as the BMI increases, so does the risk of diseases associated with obesity (Mcardle, Katch, \& Katch, 2003).

In humans, obesity is associated with increased blood pressure, coronary heart disease, and right 
ventricle hypertrophy all of which are important causes of heart failure (Alpert, 2001). The potential effects of obesity on the cardiovascular system of cats and dogs include increased heart rate, high blood pressure, increased thickness of the left ventricular free wall at diastole and systole (LVFWd and LVFWs, respectively), increased angiotensinogen levels, increased activity in the $S R A A$ gene, increased sodium entrapment due to the action of aldosterone, increased aldosterone-mediated inflammation, fibrosis, and oxidative stress, and increased cardiac remodeling (Chandler, 2016).

Obese cats are occasionally taken for consultations to cardiologists because of a noticeable heart enlargement on radiographs. These animals present a slight increase in the heart silhouette measurements because of the presence of pericardial fat. In some cases, the fat creates a double-density effect on the heart silhouette, but others require the use of echocardiography to differentiate between fat tissue and the myocardium. Some cats with much substernal fat also present tracheal elevation. However, on echocardiographic images, these animals present normal wall thickness, chamber dimensions, and contractility. The main difference observed is increased precordial dimensions due to the accumulation of substernal and subcutaneous fat (Litster \& Buchanan, 2000a).

Body weight has a clinically significant effect on echocardiographic measurements in cats, as shown in a study of 19,866 cats (Häggström et al., 2016). All echocardiographic measurements, except for fractional shortening, increased with body weight, thereby revealing an allometric relationship between body weight and echocardiographic parameters. However, a limitation of that study was the exclusion of the BCS as a parameter, which prevented an analysis of the effects of obesity on cardiac measurements (Toll et al., 2010).

Therefore, the aim of this study was to investigate the effects of obesity on cardiovascular parameters in cats.

\section{Material and Methods}

Animals

This study was conducted at the Veterinary Hospital maintained by the School of Veterinary Medicine and Animal Science, Botucatu, Brazil, between September 2015 and June 2017. It was approved by the Ethics Committee for the Use of Animals under protocol number 0176/2016 - CEUA.

We assessed 40 mixed-breed cats without the use of sedatives or tranquilizers, and divided them into two groups: Obese $(n=20)$ and Control $(n=20)$. Body weight was determined using digital scales. The animals were positioned at the center of the scales, and their weight was measured in kilograms $(\mathrm{kg})$. To determine the BCS, the cats were observed from the dorsal and profile views and palpated. The BCS of the animals was classified on a scale ranging from 1 to 9 points (Lund, Armstrong, Kirk, \& Klausner, 2005). The animals in the Control group had a BCS of 5 and those in the Obese group had a BCS of 8 or 9 .

The BMI was calculated on the basis of the length of the lower part pelvic limb (from the middle of the kneecap to the dorsal edge of the heel) and the circumference of the rib cage at the $9^{\text {th }}$ rib, both of which were measured in centimeters $(\mathrm{cm})$. The body fat content, which should be between 15 and 30\%, was calculated using the following equation: [(rib cage/0.7062) - limb/0.9156] - limb (Hawthorne \& Butterwick, 2000).

\section{Radiographic examination}

Chest radiographs were acquired immediately after echocardiography in two views (lateral and ventrodorsal). The animals were manually restrained without sedatives and were placed in the right lateral decubitus position with the thoracic limbs extended to avoid overlapping and to ensure the thoracic cavity was symmetric. The examination was conducted using a fixed X-ray unit DR-R (GE, Beijing, China) with a $150 \mathrm{kVp} / 500 \mathrm{~mA}$ high- 
frequency generator. The animals' heads were extended slightly to avoid tracheal dislocation.

Vertebral heart size (VHS) was determined as the sum of the apex-base length with the maximum craniocaudal width of the heart, measured perpendicularly to each other, in comparison with the length of the vertebral bodies from the cranial side of the fourth thoracic vertebra. The values were expressed in vertebral units (v) (Coté, Macdonald, Meurs, \& Sleeper, 2011). The technique employed was defined by the technician conducting the examination, and it depended on the body size and state of the animals. The measurements started from $65 \mathrm{kV}$ and $4.0 \mathrm{mAs}$ for the lateral view.

The amount of subcutaneous fat was measured in the ventrodorsal view, at the level of the sixth rib on the left side of each animal's thorax, by using a software for viewing and editing Digital Diagnostic Radiography System (GE Hualun Medical Systems Co., Ltd, Beijing, China). The values were expressed in millimeters $(\mathrm{mm})$.

\section{Echocardiographic examination}

The animals underwent echocardiographic examination using an ultrasound device with the Doppler function and a multifrequency sectorial transducer $(5-8 \mathrm{MHz})$ in the bidimensional mode $\left(\right.$ MyLab $^{\mathrm{TM}}$ Alpha, Esaote ${ }^{\odot}$, Genoa, Italy). The animals were manually restrained on the examination table without sedatives, and were placed in the left and right lateral decubitus positions. The left and right thoracic regions were shaved and gel was applied to improve the conduction of ultrasound waves.

The echocardiographic examinations were conducted in the bidimensional mode (mode B) and unidimensional mode (mode $\mathrm{M}$ ). The images were acquired through the right parasternal window (long axis: exit from the left ventricle; short axis: level of the papillary and aortic muscles). The images were initially acquired in mode B (long axis) for analyzing the anatomical relationships, contractility, valve morphofunctional aspects, and regurgitations.

Mode $\mathrm{M}$ measurements were taken along the short axis at the level of the tendinous chords and included the left ventricular internal diameter at diastole (LVIDd) and at systole (LVIDs), LVFWd and LVFWs, and interventricular septum at diastole (IVSd) and at systole (IVSs). We also measured the fractional shortening of the left ventricle (FS\%); the left atrium (LA) and aorta (Ao) diameters at diastole; and the left atrial-to aortic root diameter ratio (LA:Ao) at the right parasternal window, with the short axis at the level of the aorta (Boon, 2011). The normal values for the echocardiographic parameters adopted for the feline species followed those described by Boon (2011).

\section{Systolic arterial pressure}

Systolic arterial pressure (SAP) was assessed in 15 obese cats ( 7 females and 8 males) by using the Doppler method. The cats were placed in the lateral decubitus position and a cuff of adequate size was placed on the middle third of the radiusulna. To avoid stress to the animal and interferences during the measurements, the blood pressure was measured before the ambulatory echocardiography and radiography examinations in a quiet and calm location after preconditioning. Five measurements were taken for each animal, and the average values were recorded. Outliers were excluded from the final count.

\section{Statistical analysis}

We conducted a descriptive statistical analysis for each of the variables studied, including their mean, standard deviation, and median values. The normality test chosen was the KolmogorovSmirnov test. To verify the differences between the Obese and Control groups regarding the clinical (BCS, BMI, body weight, SAP, and VHS) and echocardiographic (LVIDd, LVIDs, LVFWd, LVFWs, IVSd, IVSs, FS\%, LA, Ao, and LA:Ao) variables, we employed the t-test. 
To assess the echocardiographic variables according to the comparison groups (Control versus Obese), we adopted a completely randomized design according to the model specified below:

$$
\mathrm{Y}_{\mathrm{ij}}=\mu+\mathrm{G}_{\mathrm{i}}+\mathrm{e}_{\mathrm{ij}}
$$

where $Y_{i j}$ is the value observed for the variable in question (related to the echocardiographic parameter) for animal $j$ in group $i$; $\mu$ is the constant inherent to all observations (mean); $\mathrm{G}_{\mathrm{i}}$ is the effect of the comparison group $\mathrm{i}$, in which $\mathrm{i}=1$ (Control) or 2 (Obese); and $\mathrm{e}_{\mathrm{ij}}$ is the experimental error associated with animal $\mathrm{j}$ and group $\mathrm{i}$, supposedly $\operatorname{NIID}\left(0, \sigma_{\mathrm{e}}^{2}\right)$.

To assess the behavior of the echocardiographic variables as functions of body weight, BCS, BMI, and age, we employed regression analyses to identify possible functional relationships between the groups and these variables. To choose the most adequate model, we employed the results of the analysis of variance for regression, the significance of the regression coefficient, and the increment in the multiple coefficient of determination $\left(\mathrm{R}^{2}\right)$.

We conducted Pearson's test to establish a correlation between body weight and SAP, and all analyses were conducted using the software SAS version 9.4, with the procedure PROC MIXED (Statistical Analysis System Institute [SAS Institute], 2009). The results were considered significant when $\mathrm{p}$ was lower than $5 \%(\mathrm{p}<0.05)$.

\section{Results}

Body Weight, BCS, BMI, and SAP

Among the animals included in the study, 20 cats presented obese body conditions $(\mathrm{BCS}=8$ or 9$)$ and 20 presented adequate scores $(\mathrm{BCS}=5)$ (Control). Both groups had 8 females and 12 males.

The age of the animals in the study varied between 2 and 12 years old. The average age of the animals in the Obese and Control groups was $6.8 \pm$ 3.0 and $4.7 \pm 2.4$ years old, respectively, revealing a statistical difference $(\mathrm{p}=0.018)$. All obese animals had been castrated, while $30 \%$ of the Control group $(n=6)$ had not been castrated.

In the clinical evaluation, the average body weight $(\mathrm{kg})$ of the cats in the Obese and Control groups was $6.1 \pm 1.4$ and $4.3 \pm 0.7$, respectively. These values were statistically different from each other $(p<0.001)$. The average BCS was $8.5 \pm 0.5$ in the Obese group and $5.0 \pm 0.0$ in the Control group, also showing a statistical difference $(p<0.001)$. The average BMI values for animals in the Obese and Control groups was $39.7 \pm 11.3$ and $25.9 \pm 5.1$, respectively. Of the obese cats assessed, $85.0 \%$ $(\mathrm{n}=17)$ presented BMI values above normal (above 30) (Hawthorne \& Butterwick, 2000). The values were also statistically different between the groups $(\mathrm{p}<0.001)$ (Table 1).

Table 1

Clinical parameters in both different groups of cats

\begin{tabular}{cccc}
\hline \multirow{2}{*}{ Parameters } & \multicolumn{2}{c}{ Groups } & P \\
\cline { 2 - 4 } & Control & Obese & $<0.001$ \\
\hline Body Weight $(\mathrm{Kg})$ & $4.3 \pm 0.7$ & $6.1 \pm 1.4$ & $<0.001$ \\
BCS & $5.0 \pm 0.0$ & $8.5 \pm 0.5$ & $<0.001$ \\
BMI & $25.9 \pm 5.1$ & $39.7 \pm 11.3$ & 0.158 \\
VHS & $7.8 \pm 0.4$ & $8.1 \pm 0.6$ & 0.010 \\
SAP (mmHg) & $126.1 \pm 19.7$ & $151.2 \pm 29.0$ & $<0.001$ \\
Subcutaneous fat (mm) & $13.6 \pm 3.4$ & $32.2 \pm 16.5$ & \\
\hline
\end{tabular}

T test; significance level $\mathrm{p}<0,05$; BCS: body condition score; BMI: body index mass; VHS: vertebral heart size, SAP: Systolic Arterial Pressure. 
Considering the measurement of systemic blood pressure in animals in general, cats did not exhibit stress or major discomfort during the procedure. SAP was statistically higher in the Obese group (Table 1). In this group, the incidence of high blood pressure (SAP $\geq 150 \mathrm{mmHg}$ ) was $40 \%(\mathrm{n}=6)$, and presented a strong positive correlation with increases in body weight $(\mathrm{r}=0.496 ; \mathrm{p}=0.005)$.

\section{Radiographic examination}

On chest radiographic examinations, animals in the Obese group presented average VHS

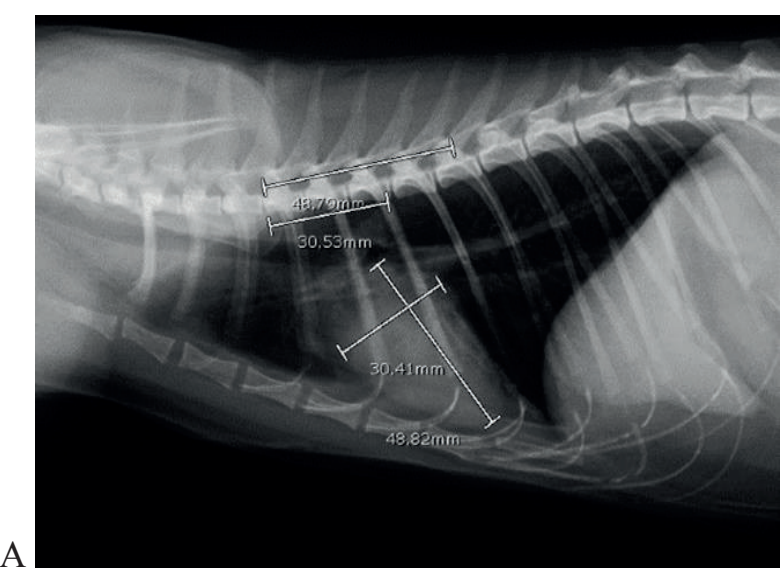

A: Control group; B: Obese group. measurements (Figure 1B) of $8.1 \pm 0.6$, which were higher than the average measurements of animals in the Control group $(7.8 \pm 0.4)$. This difference, however, was not statistically significant $(\mathrm{p}<0.05)$. We also measured, in millimeters, the thickness of each animal's subcutaneous fat layer (Figure 2A, 2B). The Obese group presented average values of $32.2 \pm 16.5$, while the Control group presented average values of $13.6 \pm 3.4$, revealing a statistical difference between the groups $(\mathrm{p}<0.001)$.

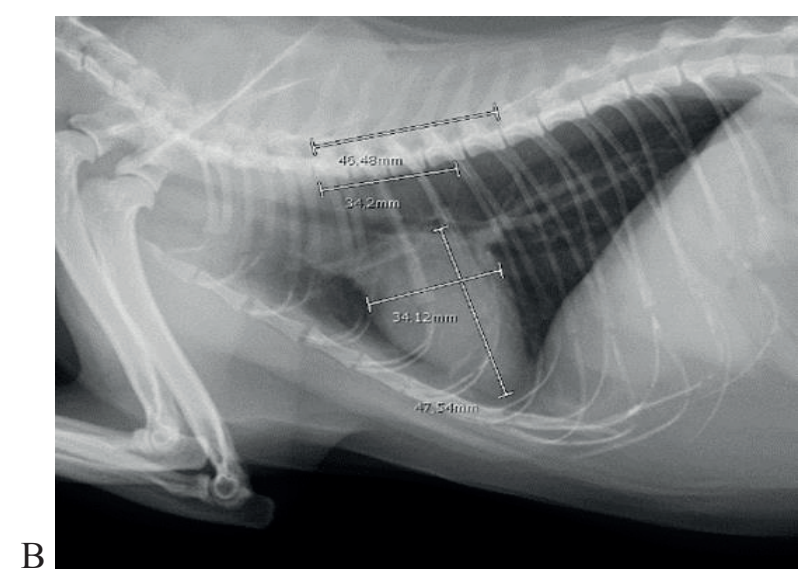

Figure 1. Determination of cats' cardiac size according to VHS (vertebral heart size) method.
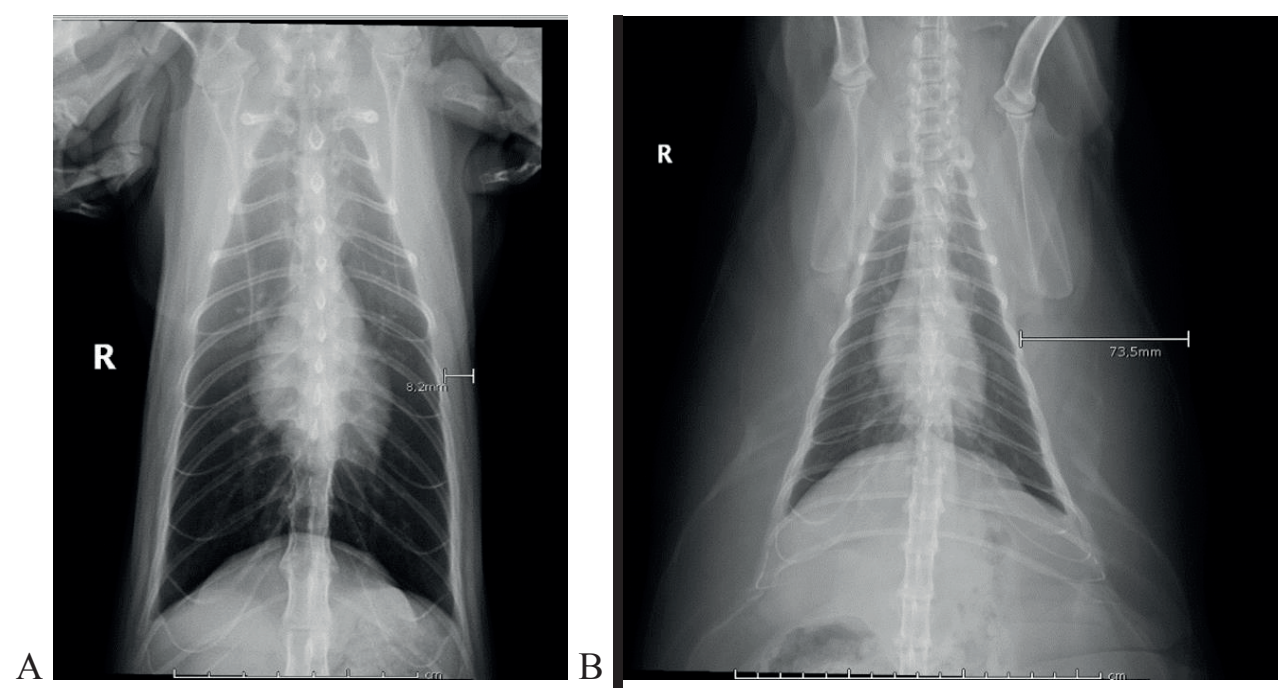

Figure 2. Subcutaneous fat measurement on radiographic examination in a cat of Control group (A) and Obese group (B). 


\section{Echocardiographic examination}

The LVFWd measurements for both groups were statistically different and significantly higher in the Obese group (Table 2). For the remaining parameters assessed, except for IVSd, the average values for the Obese group were higher than those for the Control group, albeit without significant statistical differences.

Table 2

Echocardiographic parameters and their distribution in different groups of cats

\begin{tabular}{|c|c|c|c|c|c|c|}
\hline \multirow{2}{*}{ Parameters } & \multicolumn{2}{|c|}{ Groups } & \multicolumn{2}{|c|}{ CI 95\% } & \multirow{2}{*}{$\mathrm{P}$} & \multirow[b]{2}{*}{ Reference* } \\
\hline & Obese & Control & Obese & Control & & \\
\hline Ao $(\mathrm{cm})$ & $0.86 \pm 0.15$ & $0.83 \pm 0.13$ & $0.79-0.93$ & $0.77-0.90$ & 0.500 & $0.60-1.20$ \\
\hline $\mathrm{LA}(\mathrm{cm})$ & $0.92 \pm 0.12$ & $0.86 \pm 0.12$ & $0.86-0.97$ & $0.80-0.92$ & 0.157 & $0.70-1.70$ \\
\hline LA/Ao & $1.06 \pm 0.14$ & $1.03 \pm 0.11$ & $1.00-1.13$ & $0.97-1.08$ & 0.379 & $0.80-1.79$ \\
\hline LVIDd (cm) & $1.38 \pm 0.24$ & $1.28 \pm 0.31$ & $1.13-1.44$ & $1.27-1.50$ & 0.256 & $1.08-2.14$ \\
\hline LVIDs (cm) & $0.65 \pm 0.24$ & $0.63 \pm 0.30$ & $0.48-0.77$ & $0.54-0.76$ & 0.776 & $0.4-1.12$ \\
\hline IVSd (cm) & $0.49 \pm 0.13$ & $0.51 \pm 0.10$ & $0.43-0.55$ & $0.46-0.57$ & 0.570 & $0.30-0.60$ \\
\hline IVSs $(\mathrm{cm})$ & $0.84 \pm 0.20$ & $0.83 \pm 0.15$ & $0.74-0.93$ & $0.75-0.90$ & 0.888 & $0.40-0.90$ \\
\hline LVFWd (cm) & $0.46 \pm 0.18$ & $0.33 \pm 0.15$ & $0.39-0.56$ & $0.26-0.40$ & 0.014 & $0.25-0.60$ \\
\hline LVFWs (cm) & $0.71 \pm 0.17$ & $0.64 \pm 0.13$ & $0.62-0.78$ & $0.57-0.70$ & 0.229 & $0.43-0.98$ \\
\hline FS $(\%)$ & $53.84 \pm 10.26$ & $52.17 \pm 12.78$ & $45.82-58.53$ & $49.04-58.64$ & 0.660 & $40-67$ \\
\hline Body Weight (Kg) & $6.1 \pm 1.4$ & $4.3 \pm 0.7$ & $5.45-6.78$ & $3.97-4.65$ & $<0.001$ & \\
\hline
\end{tabular}

T test; significance level p <0.05; Ao:aorta; LA: left atrium; LA/Ao: left atrial-to-aortic root diameter ratio; LVIDd: left ventricular internal diameter diastole; LVIDs: left ventricular internal diameter systole; IVSd: interventricular septum diastole; IVSs: interventricular septum systole; LVFWd: left ventricular free wall diastole; LVFWs: left ventricular free wall systole; FS: fractional shortening. *Boon (2011).

The tests employed to verify a possible correlation between the echocardiographic parameters, BMI, BCS, and body weight showed a positive relationship between LVFWd, body weight, and BCS; Ao, body weight, and BMI; LA and body weight; and LVIDd and body weight. A quadratic relationship was also observed between LA:Ao and body weight. In addition, the relationship between LVFWd and BMI, although not considered significant in this study, presented $\mathrm{p}$ values slightly above 0.05 .

\section{Discussion}

The consequences of obesity in domestic cats have been widely documented in the literature, but these have rarely been systematically studied.
Obesity predisposes cats to cardiovascular and respiratory alterations, diabetes mellitus, high blood pressure, osteoarticular injuries, hepatic lipidosis, immunosuppression, reproductive disorders, anesthetic and surgical complications, dyslipidemia, and incontinence and urinary tract stones; it also complicates the execution of exploratory procedures such as auscultation, palpation, and radiography (Toll et al., 2010; Lund et al., 2005; Weeth, 2016).

When assessing the age of the studied animals, we observed that $50 \%(n=10)$ of the animals in the Obese group were between 7 and 11 years old, and the other animals had ages close to this range. This is in accordance with the literature, which points towards most afflicted animals being middle-aged (Lund et al., 2005). 
During the nutritional assessment of patients, the measurement of body weight is considered a low-precision method to classify malnutrition/ obesity (Zoran, 2010). The use of the BCS and BMI as parameters allows the detection of obesity with more precision (Lund et al., 2005; Hawthorne $\&$ Butterwick, 2000). A previous study aiming to establish the relationship between echocardiographic parameters and body weight in many cats was limited by the lack of precise assessment of the animals' nutritional state. The authors assessed only body weight to verify the influence of body size on cardiac dimensions, and this did not allow determining the influence of obesity over these parameters (Häggström et al., 2016).

The current study included animals considered obese as well as animals in ideal body condition, determined through the assessment of the BCS and BMI. These are considered practical, easy-to-use, and reliable methods to assess the nutritional state of cats and dogs (Lund et al., 2005; Hawthorne \& Butterwick, 2000).

Similarly, this study showed a correlation between body weight and some echocardiographic measurements (LVFWd, LVIDd, and LA:Ao ratio). However, the other parameters employed in the nutritional assessment of the animals (BCS and BMI) also correlated to the measurements, in addition to showing a statistically significant difference between the Obese and Control groups $(p<0.001)$. These findings highlight the importance of an adequate nutritional assessment to verify the impact of obesity on the cardiovascular system.

On chest radiography, animals in the Obese group presented higher VHS values than did animals in the Control group, despite the absence of a statistical difference $(p>0.05)$. However, other studies noted no increase in the VHS values of obese cats (Litster $\&$ Buchanan, 2000a). The average measurements for the Obese group were above the reference values for the species (7.5 \pm 0.3$)$ (Litster \& Buchanan, 2000b). On the other hand, the Control group (about $89 \%$ of the animals) presented slightly increased values when compared to the adopted reference value, but the mean and standard deviation were still within the range of the reference value. This may be explained by the fact that obese cats have excess pericardial fat, which causes the cardiac silhouette to appear larger than it actually is, thereby obscuring the cranial margin of the heart and complicating the identification of the real cardiac silhouette. The accumulation of subcutaneous fat also lowers the quality of radiographic images and contributes to an overestimation of heart size (Coté et al., 2011).

On visual examination, some animals presented an apparent augmentation of the cardiac silhouette, which has previously been described in the literature for overweight animals. Importantly, this augmented silhouette may be the result of an accumulation of pericardial fat. In the absence of double radiopacity in the radiographic image, only an echocardiogram can confirm this alteration, thereby highlighting the importance of this examination (Litster \& Buchanan, 2000a). We also measured the amount of subcutaneous fat in the chest area, and the Obese group presented values significantly higher than the Control group did $(\mathrm{p}<0.001)$.

The cardiovascular system is one of the most affected by obesity, and such effects have already been established in humans. Studies have shown a positive relationship between the body weight of cats and the cardiac measurements obtained using echocardiography (Häggström et al., 2016). Consistent with the findings of this study, other studies have also shown an increase in some morphometric parameters during the echocardiographic examination of obese cats (Champion, 2011).

Another study assessed the echocardiographic measurements of 10 obese cats, but did not observe alterations in the thickness of the LVFWd or LVFWs when compared to the corresponding values of normal cats. These results are different from those observed in the current study, because the LVFWd 
measurements in our study were higher in Obese cats than in Control cats (Litster \& Buchanan, 2000a).

The implications of obesity on the feline cardiovascular system assessed using echocardiographic assessments are yet to be fully established, and studies on this subject are scarce. By correlating the echocardiographic measurements of cats with their body weight, we determined that practically all measurements conducted during the examination, except for fractional shortening, increased with the animal's body weight (Häggström et al., 2016). The measurements of obese animals in this study, despite not being statistically different $(p<0.05)$ and being within the normality parameters for the species, were above the average values of the Control group for all echocardiographic measurements except for IVSd (Boon, 2011). Only the LVFWd values presented a significant increase in the Obese group. Similarly, in another study, the LVFWd values were also significantly increased in addition to the IVSd values, thereby leading to the conclusion that obesity may be associated with cardiac remodeling (Champion, 2011).

Results of previously published studies have shown that body weight has a clinically relevant impact on most of the standard echocardiographic measurements in cats, indicating that a fixed reference interval may not be adequate for the species (Häggström et al., 2016). This study also obtained similar results, showing a positive relationship between some echocardiographic measurements (LA, Ao, LVIDd, LVFWd, and LA:Ao) and body weight.

Other measurements have also shown a positive relationship with the animal's cardiac parameters, namely, a positive relationship between the BCS and LVFWd and a positive relationship between the BMI and Ao. However, further studies with more animals are warranted to establish a relationship between the natural fluctuation of these parameters and the variation of echocardiographic parameters in cats.
The values normally employed as reference parameters in clinical routine do not include variations between breeds, sizes, or nutritional state (Boon, 2011). However, body weight has been shown to influence echocardiographic measurements (Häggström et al., 2016). Therefore, we question why such parameters should not be established according to the BCS and BMI, given the relationship between these parameters and cardiac measurements shown in this study.

A positive correlation was observed between SAP and body weight, in addition to the fact that obese animals presented systemic blood pressure values significantly higher than those in the Control group. Obesity may induce hemodynamic dysfunctions characterized by increased systolic volume, redistribution of blood volume, and increased cardiac output (Frohlich \& Susic, 2008). The normal compensatory response to increased cardiac output and systolic volume should be the decrease in peripheral vascular resistance, which is generally inappropriate in obese individuals, contributing to the occurrence of systemic arterial hypertension (Messerli et al.,1981).

Another important observation was that the obese animals in this study had an increase in the mean values of the LVFW relative to those in control cats. This fact may be attributed to the association with increased blood pressure values, with the heart being a target organ of systemic arterial hypertension. Moreover, systemic arterial hypertension can lead to lesions in target organs, and the sustained increase in blood pressure causes cardiac changes, such as left ventricular hypertrophy and heart failure (Acierno et al., 2018). Eccentric ventricular hypertrophy may lead to cardiomegaly, which can be assessed using chest radiography and VHS measurement (Litster \& Buchanan, 2000b). Thus, we may infer that obesity can lead to cardiovascular dysfunction in cats.

The most common method employed for studying the cardiovascular system in veterinary 
medicine is to assess a population of presumably healthy individuals and to calculate a reference interval based on the standard deviation of the mean values for that population (Häggström et al., 2016). This concept opens doors for further studies aiming to establish a relationship between obesity and echocardiographic measurements, and the current study findings serve as a foundation for in-depth research into this subject.

One of the limitations of this study was the low number of animals included. Larger studies are needed to prove that obesity promotes alterations in the cardiovascular function of cats. In addition, the use of a regression analysis and/or allometric relationship could have been useful for the inclusion of prediction intervals in the study (Häggström et al., 2016). The variation coefficient (analysis of the echocardiographic measurements by two or more reviewers) is also an important tool that would have added greater credibility to the study.

\section{Conclusions}

Obesity has been shown to influence the cardiac function in cats, since the values for some echocardiographic parameters presented differences when compared to those of normal cats. In addition, a positive relationship was observed between body weight, BCS, BMI, SAP, and some cardiac dimensions. Further studies are needed to evaluate precise methods to describe the association between body weight and cardiac dimensions in cats, as well as to establish an adequate relationship between the accumulation of fat and echocardiographic parameters considering the nutritional state of the animals.

\section{Acknowledgments}

We would like to thank Editage (www.editage. com) for English language editing.

\section{References}

Acierno, M. J., Brown, S., Coleman, A. E., Jepson, R. E., Papich, M., Stepien, R. L., \& Syme, H. M. (2018). ACVIM consensus statement: Guidelines for the identification, evaluation, and management of systemic hypertension in dogs and cats. Journal of Veterinary Internal Medicine, 32(6), 1803-1822. doi: 10.1111/jvim. 15331

Alpert, M. A. (2001). Obesity cardiomyopathy: pathophysiology and evolution of the clinical syndrome. The American Journal of the Medical Sciences, 321(4), 225-236. doi: 10.1097/00000441200104000-00003

Boon,J.A.(2011). Manual ofveterinaryechocardiography (2nd ed.) Baltimore: Wiley-Blackwell.

Champion, T. (2011). Efeitos da obesidade e do sobrepeso sobre parâmetros cardiovasculares e respiratórios em gatos. Tese de doutorado, Faculdade de Ciências Agrárias e Veterinárias, Universidade Estadual Paulista, Jaboticabal, SP, Brasil.

Chandler, M. L. (2016). Impact of obesity on cardiopulmonary disease. Veterinary Clinics of North America: Small Animal Practice, 46(5), 817830. doi: 10.1016/j.cvsm.2016.04.005

Clark, M., \& Hoenig, M. (2016). Metabolic effects of obesity and its interaction with endocrine diseases. Veterinary Clinics of North America: Small Animal Practice, 46(5), 797-815. doi: 10.1016/j. cvsm.2016.04.004

Coté, E., Macdonald, K. A., Meurs, K. M., \& Sleeper, M. M. (2011). Feline cardiology. Chichester: John Wiley \& Sons.

Diez, M., \& Nguyen, P. (2006). The epidemiology of canine and feline obesity. Waltham Focus, 16(1), 2-8. Recuperado de http://citeseerx.ist.psu.edu/ viewdoc/download?doi=10.1.1.799.7498\&rep=rep1 $\&$ type $=p d f$

Frohlich, E. D., \& Susic, D. (2008). Mechanisms underlying obesity associated with systemic and renal hemodynamics in essential hypertension. Current Hypertension Reports, 10(2), 151-155. doi: 10.1007/s11906-008-0028-8

Häggström, J., Andersson, A. O., Falk, T., Nilsfors, L., Olsson, U., Kresken, J. G.,... Ljungvall, I. (2016). Effect of body weight on echocardiographic measurements in 19.866 pure-bred cats with or without heart disease. Journal of Veterinary Internal Medicine, 30(5), 1601-1611. doi: 10.1111/ jvim.14569 
Hawthorne, A. J., Butterwick, R. F. (2000). Predicting the body composition of cats: development of a zoometric measurement for estimation of percentage body fat in cats. Journal of Veterinary Internal Medicine, 14(3), 349-365.Recuperado de https:// eurekamag.com/research/035/534/035534976.php

Linder, D., \& Mueller, M. (2014). Pet obesity management - beyond nutrition. Veterinary Clinics of North America: Small Animal Practice, 44(4), 789-806. doi: 10.1016/j.cvsm.2014.03.004

Litster, A. L., \& Buchanan, J. W. (2000a). Radiographic and echocardiographic measurement of the heart in obese cats. Veterinary Radiology Ultrasound, 41(4), 320-325. doi: 10.1111/j.1740-8261.2000.tb02080.x

Litster, A. L., \& Buchanan, J. W. (2000b). Vertebral scale system to measure heart size in radiographs. Journal of the American Veterinary Medical Association, 216(2), 210-214. doi: 10.2460/javma.2000.216.210

Lund, E. M., Armstrong, P. J., Kirk, C. A., \& Klausner, J. S. (2005). Prevalence and risk factors for obesity in adult dogs from private US veterinary practices. Internal Journal Applied Research Veterinary Medicine, 4(2), 177-186. Recuperado de http:// jarvm.com/articles/Vol4Iss2/Lund.pdf

Mcardle, W. D., Katch, F. I., \& Katch, V. L. (2003). Fisiologia do exercício: energia, nutrição $e$ desenvolvimento humano (5nd ed.). Rio de Janeiro: Guanabara Koogan.
Messerli, F. H., Christie, B., Decarvalho, J. G. R., Aristimuno, G. G., Suarez, D. H., \& Frohlich, E. D. (1981). Obesity and essential hypertension: hemodynamics, intravascular volume, sodium excretion and plasma rennin activity. Archives of Internal Medicine, 141(1), 81-85. doi: 10.1001/ archinte.141.1.81

Statistical Analysis System Institute (2005). Inc. SAS/ STAT 9.4. User's guide. Cary: SAS Publishing.

Toll, P. W., Yamka, R. M., Schoenherr, W. D., \& Hand, M. S. (2010). Obesity. In M. S. Hand, C. D. Thatcher, R. L. Remillard, P. Roudebush, B. J. Novotny. Small animal clinical nutrition (5nd ed., pp.501-541). Topeka, Kansas: Mark Morris Institute.

Weeth, L. P. (2016). Other risks/possible benefits of obesity. Veterinary Clinics of North America: Small Animal Practice, 46(5), 843-53. doi: 10.1016/j. cvsm.2016.04.007

Zoran, D. L. (2009). Feline obesity: clinical recognition and management. Compendium on Continuing Education for Veterinarians, 31(6), 284-293. Recuperado de https://pdfs.semanticscholar. org/7494/ 2ad7b2e7fe5fec3cfcade55a01faf39e4fcf. pdf?_ga=2.8263409.215411449.1581081054375132374. 1543523887

Zoran, D. L. (2010). Obesity in dogs and cats: a metabolic and endocrine disorder. Veterinary Clinics of North America: Small Animal Practice, 40(2), 221-239. doi: 10.1016/j.cvsm.2009.10.009 
